\title{
Sutural bones: a literature review
}

\author{
Rafael Romero-Reverón ${ }^{1}$ (D), Luis A. Arráez-Aybar² (D) \\ ${ }^{1}$ Department of Human Anatomy, Fosé María Vargas Medical School, Faculty of Medicine, Central University of Venezuela, Caracas, Venezuela \\ ${ }^{2}$ Department of Anatomy and Embryology, Faculty of Medicine, Complutense University of Madrid, Madrid, Spain
}

\begin{abstract}
Using standard search engines PubMed, Scopus, Scielo, Cochrane, Science Direct and Medline, 433 articles were found to evaluate the information about sutural bones. Thirty-six articles that match our stated objectives about sutural bones were analyzed. Data were evaluated in the current medical literature for their historical aspects, anatomical classification, development, clinically significance and their presence in some bone dysplasias. There is still dispute on whether sutural bone development is influenced by genetic or external factors. Sutural bones are a known sporadic occurrence in the human cranium and do not predispose a person to any particular disease. Their presence, however, is commonly used as a useful marker of some underlying genetic disorders.
\end{abstract}

Keywords: cranium, human, interparietal bone, sutural bone, Wormian bones

Anatomy 2019;13(1):61-65 @2019 Turkish Society of Anatomy and Clinical Anatomy (TSACA)

\section{Introduction}

The human cranium is the most studied and documented part of the vertebrate skeleton and also rather important and complex, possibly because of its relationship with the nervous system. It can be described, broadly, as a container for more or less rigid tissues, being the encephalon, organs of vision, smell and inner ear. It also serves to support the external organs of digestive apparatus and the respiratory apparatus and defines the direction of a human's movement.

The human cranium is composed of numerous bones that fuse together after birth in addition to the regular centers of ossification of the cranium. Sutural bones can be isolated or, occasionally, found in cranial sutures and fontanels. They are supernumerary, irregular, accessory and abnormal small bones interposed between cranial bones, most commonly located in the lambdoid suture (Figure 1). Sutural bones result from the formation of abnormal ossification centers in the cranium that develops in addition to those seen normally. They are poorly reported although they are quite common. Sutural bones have been documented on most mammals and in hominids, so they are not exclusive to the modern human cranium.

Sutural bones are studied and reported as ethnic variables, being of interest in matters of human anatomy, physical anthropology, forensic medicine and radiology.

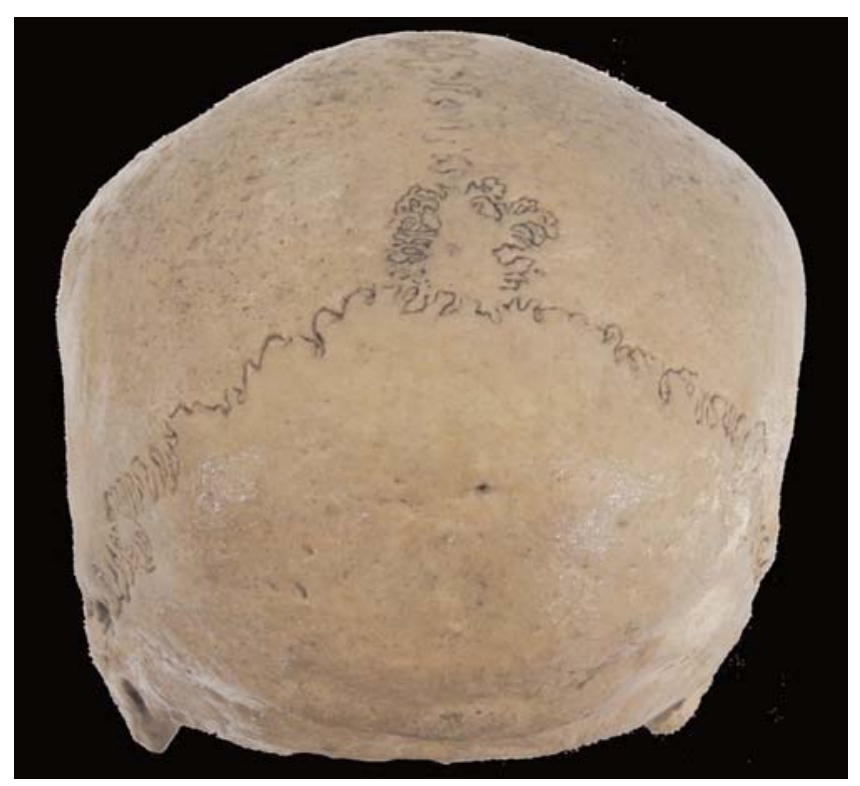

Figure 1. Sutural fontanelle bones in lambdoid suture (With kind permission of the Museum Villa Julian Complutense University of Madrid, Spain). [Color figure can be viewed in the online issue, which is available at www.anatomy.org.tr]

The origin of sutural bones remains unclear, but mechanical, pathological and genetic factors have been proposed as the primary causes of their incidence. The main objec- 
tive of this article was to review the information about sutural bones in current medical literature.

\section{Materials and Methods}

This study was undertaken because many aspects of sutural bones are not yet entirely clear. For the article, the authors proceeded as follows: The criterion for including articles was that they be freely available on the web, and on the other hand the exclusion criteria was that the data can obtained from paid subscription or related. The search engines PubMed, Scopus, Scielo, Cochrane, Science Direct and the Medline were consulted and 433 articles were reviewed thoroughly in the scientific literature in both English and Spanish. The following keywords were used: sutural bones, ossa Suturalia, Wormian bones, bone dysplasia and interparietal (Inca) bone. Subsequently, the authors decided to focus on 36 articles and a inferential statistical analysis was applied to data obtained for sutural bones, their historical aspects, anatomical classification, clinically significant development, and their presence in some bone dysplasias. The period of research articles was from 1965 to 2018.

\section{Results}

\section{Sutural Bones: Historical Aspects}

Sutural bones appear to be as old as man himself: they have even been observed in Australopithecine cranial fragments from Makapansgat. ${ }^{[1]}$ They were named Wormian bones after the Danish anatomist, Olaus Wormius, a medical doctor at the University of Copenhagen. ${ }^{[2]}$ In 1643 , he provided a detailed description in a letter in Latin to his colleague Thomas Bartholin, then in Padua, Italy. After receiving the letter, Bartholin himself decided to call sutural bones "ossa Wormia" (Wormian bones). However, Wormian bones had been described even before Olaus Wormius' time. The first description is attributed to Hippocrates himself and the first diagrams of the cranial structure can be found in Avicenna's Canon. ${ }^{[3]}$ Sutural bones were also mentioned by Paracelsus, who named a bone located in the posterior fontanel the "ossiculum antiepilepticum", ${ }^{[4]}$ and D'Andemach Gonthier who described them in detail. ${ }^{[5,6]}$ One of the first to associate sutural bones with cerebral disorders was Vesalius. In the international anatomical nomenclature, sutural bones are called ossa suturalia and are marked as A02.1.00.043. ${ }^{[7]}$ However, these bones are still denominated "Wormian bones" in most research articles, e.g. in references of this review.

\section{Anatomical Classification}

Sutural bones are detached portions of the primary ossification centers of the adjacent membrane bones in the cra- nium. They articulate with the surrounding bones by sutures with indentations that are more complex on the outer surface of the human cranium than on the inner one. ${ }^{[8,9]}$

Sutural bones are found in both sexes, as well as on both sides of the cranium. They exhibit different irregular shapes: round, oval, oblong, triangular, quadrilateral and polygonal, and can vary in dimension from under 1 $\mathrm{mm}$ to $5 \times 9 \mathrm{~cm}$. The denominations used for sutural bones depend on the site where they actually appear: the names given are generally derivatives of the suture or sutures they are in contact with or the centre of ossification or fontanel where they originate. Although some locations of sutural bones are more common, these bones do not receive particular names in the international anatomical nomenclature, because they vary in number, size, shape and thickness from cranium to cranium. Notwithstanding the above, some authors name the preinterparietal bone or the Inca bone - a triangular sutural bone located at the previous site of the posterior fontanel. It is so called because of its incidence in Inca bones in Peruvian mummies. ${ }^{[1,11]}$

About half of the sutural bones are located in the lambdoid suture and fontanel (and the masto-occipital suture). The second most common site of occurrence (about 25\%) is in the coronal suture ${ }^{[12,13]}$ The remaining occur in any remaining suture or fontanel. ${ }^{[14]}$ Knowledge of this variation is very important for neurosurgeons, radiologists and anthropologists, among others.

Sutural bones are classified into true and false variants. ${ }^{[6,15]}$ False sutural bones are ossification centers not welded to independent bones, such as occipital or temporal bones. True sutural bones are derived from one or many points of ossification. They consist of all supernumerary developed bony parts in the marginal part of the cranial bones. ${ }^{[15,16]}$

Depending on their location, sutural bones can be true sutural bones, fontanels or isolated ones. ${ }^{[17-19]}$ True sutural bones may be sagittal bones (between the two parietal bones) or developing in the occipitoparietal sutures (Figure 2), fronto-parietal sutures, sphenoparietal sutures, petro-occipital sutures or inter-parietal sutural bones (Figure 3). Sutural fontanel bones can be found in almost all normal and abnormal craniums. They can be bregmatic, lambdoid, pteric or orbital. ${ }^{[6,19,20]}$ The isolated sutural bones are those that develop at a distance from the sutures and fontanels. They frequently take up the entire thickness of the cranium, but can also be formed only at the expense of the outer table of the cranium (exocranial); more rarely, they are formed at the expense of the inner table of the cranium (intracranial). 


\section{The Development of Sutural Bones}

Although the incidence of sutural bones is quiet common, ${ }^{[21]}$ the observational data on them is poorly reported. The cranium of the human embryo begins developing between days 23 and 26 of gestation. It can be divided into the viscerocranium, which is derived from the first three branchial arches and forms the facial skeleton and the neurocranium; this surrounds the brain and develops from the surrounding mesenchyme. ${ }^{[1,2]}$ The human cranial skeleton is composed of an assortment of neural crest- and mesoderm-derived cartilages and bones. The formation of the human cranium is a complex interaction between bony and meningeal elements. Any irregularity in these interactions may result in the incidence of sutural bones. ${ }^{[14]}$ Since sutural bones belong to the neurocranium, they share its embryology. They appear as isolated ectopic islands of intramembraneous ossifications. In the fetus, the diploë is not formed yet, and thus Sutural bones are composed of a single layer of compact bone on the dural side. ${ }^{[12]}$

Sutural bones are thought to appear in connection with increased dural strain from mechanical force, as well as with increased sutural width. In some cases, sutural bones will appear at the same time as the normal ossification centers; in others, as with some ossification centers, they will appear as a necessity for them arises. ${ }^{[7]}$ External factors, such as artificial cranial manipulations, are thought to play a significant role in the number of sutural bones present an individual cranium. These factors include mechanically induced stress owing to intentional deformation such as that practised in ancient cultures. ${ }^{[21,23]}$ It is controversial whether the development of sutural bones is influenced by genetic or external factors; nevertheless their presence is commonly used as a useful marker of some underlying genetic disorders such as imperfect osteogenesis. ${ }^{[2]}$ Researchers have shown that sutural bones located posteriorly have more of an external factor associated with them than anterior sutural bones. ${ }^{[25]}$ There is no consensus in the literature regarding the degree to which the presence and frequency of sutural bones can be attributed to external or genetic influences. ${ }^{[25,26]}$ Anthropologic research has shown that most sutural bones develop in anteroposterior deformed crania; non-deformed crania were shown to have lower incidence. Circumferentially deformed crania were found to have the lowest incidence of sutural bones. ${ }^{[27]}$

\section{Clinical Significance}

Sutural bones can be found in healthy individuals with an incidence of $8 \%$ to $15 \%$ of the population. In Bregman's study, nearly $40 \%$ of craniums contain sutural bones in the vicinity of lambdoid sutures. ${ }^{[28]}$ The incidence of sutur-

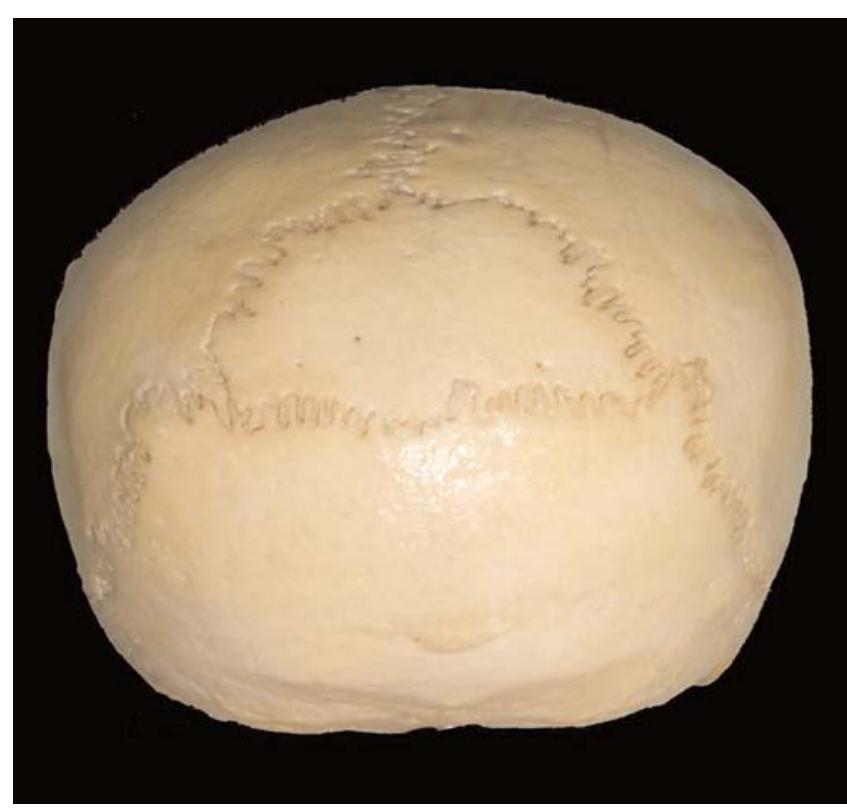

Figure 2. Occipitoparietal sutural bone (With kind permission of the Museum Villa Julian Complutense University of Madrid, Spain). [Color figure can be viewed in the online issue, which is available at www. anatomy.org.tr]

al bones has also been studied and reported as an ethnic variable: there are differences between various ethnic groups. Chinese individuals exhibit the highest incidence - as high as $80 \%$; the incidence in Indian individuals is $40 \%$ in Indian and $10 \%$ in Caucasian individuals. ${ }^{[1,22]}$ Their incidence is useful for comparative studies as an anthropological marker or an indicator of population distance. Ethnic variation in sutural bones may suggest possible genetic influences, but environmental influences can

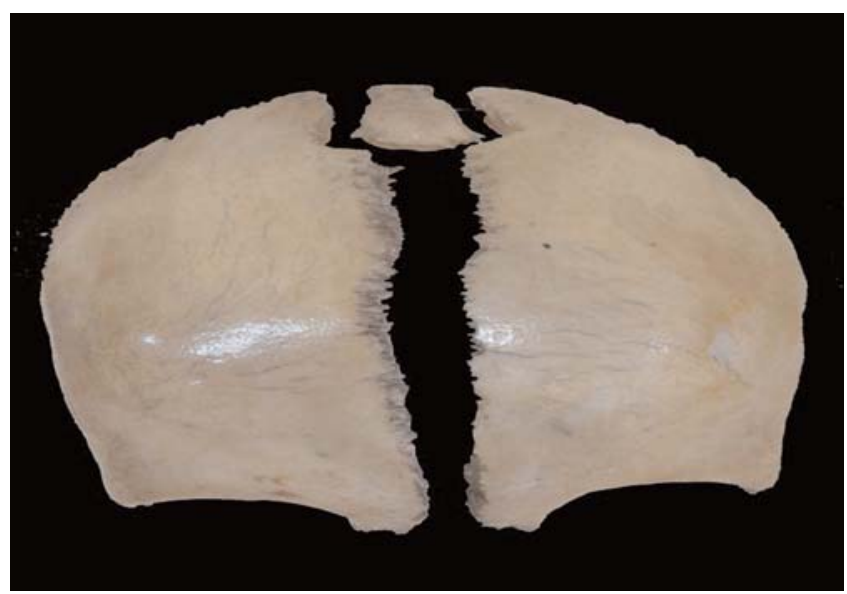

Figure 3. Interparietal sutural bone (With kind permission of the Museum Villa Julian Complutense University of Madrid, Spain). [Color figure can be viewed in the online issue, which is available at www.anatomy.org.tr] 
also play a role. Some researchers argue that males are affected more than females, while others have concluded that there is no significant difference between genders. ${ }^{[7,12,24]}$ The bones are generally found unilaterally and are more frequently located on the right side of the cranium. ${ }^{[12,24]}$ The number of sutural bones is generally limited to two or three, but more than a hundred have been found in the cranium of an adult hydrocephalic skeleton. ${ }^{[19]}$ In order to be regarded as pathologically significant, incidences of sutural bones must meet some definite criteria: they must be more than ten in number; the bones must be arranged in a general mosaic-type pattern; and their size must be larger than $6 \mathrm{~mm}$ by $4 \mathrm{~mm} \cdot{ }^{[2]]}$ The mere presence of sutural bones may be misleading: on X-ray images, they may be mistaken for fractures.

\section{Sutural Bones in Some Bone Dysplasias}

Sutural bones have been found in a diversity of congenital disorders like hypophosphatasia, imperfect osteogenesis, progeria, craniosynostosis, hypothyroidism (cretinism), cleidocranial dysostosis, rickets, pyknodysostosis (osteopetrosis acro-osteolytica), pachydermoperiostosis and others. ${ }^{[2,30]}$ Among the more common congenital disorders with presence of sutural bones are imperfect osteogenesis and craniosynostosis, which are bone dysplasia. Imperfect osteogenesis commonly occurs owing to genetic mutations. The phenotypic presentation involves extremely breakable bones and deformations in the osseous structuring of the spine and cranium. In addition, imperfect osteogenesis can cause a slow deformation of the bones of the cranium, known as a basilar abnormality. It this condition, the soft bones of the cranium cannot support the normal weight of the cranium and brain. ${ }^{[31]}$ One study has revealed that sutural bones were present in $89 \%$ of the patients with imperfect osteogenesis. ${ }^{[29]}$ Although the incidence of sutural bones is not pathognomonic of imperfect osteogenesis, it may warrant further investigation of such disorders involving defective osteogenesis. Sutural bones are also present in cases of craniosynostosis, a bone dysplasia which is a cause of early closure of fontanels in infancy, because of the effects of early fusion of the sutures which, in turn, cause abnormal dural strain in the area of the opposing fontanel. This strain can give rise to the formation of bony islands in the membranous portion of the fontanel. A study of this aspect showed that sutural bones may occupy the anterior fontanel in at least $4 \%$ of the cases of isolated sagittal craniosynostosis: this can lead to the appearance of a closed fontanel. ${ }^{[32]}$ It can occur as part of a syndrome or as an isolated defect. Craniosynostosis is called "simple" when only one suture is involved, and "compound" when two or more sutures are involved. If craniosynostosis occurs due to an intrinsic suture defect, it is named "primary craniosynostosis", while craniosynostosis resulting from another medical condition is name "secondary craniosynostosis". ${ }^{[13]}$ Morphological knowledge of sutural bones can be important for the diagnosis of these disorders, ${ }^{[3,34}$ but sutural bones, in themselves, do not carry a negative prognosis, ${ }^{[3,36]}$ and thus the prognosis will depend on the type and severity of the associated diseases.

\section{Discussion}

Sutural bones are formed due to additional ossification centers in or near sutures of the flat bones of the human cranium and are usually regarded as normal variants. They occur most frequently in the lambdoid and occipitomastoid sutures. They are found in both sexes, as well as in both sides of the human cranium. Sutural bones are classified by location in most cases, derivative from the suture next rather than shape, hence the name of this type of bone. When sutural bones occur as a normal variant, they tend to be smaller and less numerous than when they are associated with bone dysplasias.

Anatomical knowledge of sutural bones is clinically important, because their presence, and this refers mainly to bone dysplasia such as craniosynostosis and imperfect osteogenesis, is commonly used as a useful marker of some congenital disorders. Nevertheless, standing alone, their presence is not a clinically significant event for determination of any particular disease. Whether the development of sutural bones is influenced by genetic or external factors or both remains in dispute and it is still unclear why sutural bones are common in certain races.

\section{Conclusion}

Although sutural bones are poorly reported, a knowledge of them is of interest and useful to human anatomy, neurosurgery, physical anthropology, forensic medicine, craniofacial surgery, imaging medicine and legal medicine, medical research among others.

\section{Acknowledgments}

Authors thank to Professor Mérida Velasco, M.D., director of the Museum Villa Julian Complutense University of Madrid for allowed us to include in this article the images of the human cranium (Figures 1-3).

\section{References}

1. Bennett K. The etiology and genetics of wormian bones. Am J Phys Anthropol 1965;23:209-347.

2. Romero R, Arráez L. Ole Worm (1588-1654). Anatomist and antiquarian. Eur J Anat 2015;19:299-301.

3. Arráez-Aybar L, Bueno-López J, Raio N. Toledo School of Translators and their influence on anatomical terminology. Ann Anat 2015;98:21-33. 
4. Martin B, Sirinelli D, Maurin L, Carpentier E. Wormian bones in a general paediatric population. Diag and Interv Imag 2013;94:42832.

5. Testut L, Latarjet A. Tratado de anatomia humana. Tome I. Barcelona: Salvat editores; 1978. p. 187-90.

6. Kardel T, Shampo M, Kyle R, Ole Worm.-Versatile. Dedicated Danish physician. Mayo Clinic Pro 1990;65:373.

7. FCAT. Terminologia anatomica internacional. Edit Medic Panamericaa 1998;53.

8. Parker C. Wormian bones. Chicago, IL: Robert Press; 1905 [Digitalized in 2007 and made available by UCLA digital library].

9. Murlimanju B, Prabhu L, Ashraf C, Kumar C, Rai R, Maheshwari C. Morphological and topographical study of Wormian bones in cadaver dry skulls. J Morphol Sci 2011;28:176-9.

10. Marathe R, Yogesh A, Pandit S, Joshi M, Trivedi G. Inca-interparietal bones in neurocranium of human skulls in central India Neurosci Rural Pract 2010;1:14-6.

11. Cirpan S, Aksu F, Mas N. Inca bone in human skulls of the West Anatolian population. Int J Morphol 2014;32:275-8.

12. Jeanty $\mathrm{P}$, Rejane S, Turner C. Prenatal diagnosis of Wormian bones. J Ultrasound Med 2000;19:863-9.

13. Tubbs S, Bosmia A, Cohen-Gadol A. The human calvaria: a review of embryology, anatomy, pathology, and molecular development. Childs Nerv Syst 2012;28:23-31.

14. Khan A, Asari M, Hassan A. Unusual presence of Wormian (Sutural) bones in human skulls. Folia Morphol 2011;70:291-4.

15. Rouiviere H, Delmas A. Anatomía humana. Paris: Editorial ElsevierMasson; 2005. p. 82-3.

16. Latarjet M, Ruiz-Liard A. Anatomía humana. Madrid: Editorial Medica Panamericana; 2004. p. 83.

17. Gómez L. Lecciones de Anatomía humana. Osteologia I, $2^{a}$ part. Madrid: Editorial Marban; 1960. p. 240-2.

18. Orts F. Anatomia humana. Tomo I. 6th ed. Madrid: Editorial Científico-médica; 1987. p. 786.

19. Romero-Reveron R. Anatomical classification of sutural bones. MOJ Anat \& Physiol 2017;3:00101.

20. Gray H. Anatomy. Descriptive and surgical 1901 Edition. Philadelphia, PA: Running Press; 1974. p. 81.

21. García-Hernández F, Murphy-Echeverría G. Frecuency of Wormian lambdoid bone in skulls with artificial deformation in Northern Chile. Int J Morphol 2009;27:933-8.

22. Bellary S, Steinberg A, Mirzayan N, Shirak M,Tubbs S, CohenGadol A, Loukas M. Wormian bones: a review. Clin Anat 2013;26: 922-7.
23. Shapiro R, Robinson F. The os incae. Am J Roentgenol 1976;127: 469-71.

24. Semler O, Cheung MS, Glorieux FH, Rauch F. Wormian bones in osteogenesis imperfect: correlation to clinical findings and genotype. Am J Med Genet 2010;152:1681-7.

25. Sanchez-Lara P, Graham J, Hing A, Lee J, Cunnigham M. The morphogenesis of Wormian bones : a study of craniosysnostosis and purposeful cranial deformation. Am J Med Genet A 2007;143:324351.

26. Barberini F, Bruner E, Cattolari R, Franchitto G, Heyn R, Ricci F, Manzi G. An unusually wide human bregmatic Wormian bone: anatomy, tomographic description and possible significance. Surg Radiol Anat 2008;30:683-7.

27. Anton S, Jaslow C, Swartz S. Sutural complexity in artificially deformed human (Homo sapiens) crania. J Morphol 1992;214:3214.

28. Bergman R, Afifi A, Miyauchi R. Skeletal systems: Cranium. In: Compendium of human anatomical variations. Baltimore, MD: Urban \& Schwarzenberg; 1988. p. 197-205.

29. Cremin B, Goodman H, Sprenger J, Beighton P. Wormian bones in osteogenesis imperfecta and other disorders. Skelet Radiol 1982;8: 35-8.

30. Pekçevik Y, Hasbay E, Pekçevik R. Three-dimensional CT imaging in pediatric calvarial pathologies. Diagn Interv Radiol 2013;19: 48894

31. Kovero O, Pynneonen S, Kuurila-Svahn K, Kaitila I, Waltimo S. Skull base abnormalities in osteogenesis imperfecta: a cephalometric evaluation of 54 patients and 108 control volunteers. J Neurosurg 2006;105:361-70.

32. Agrawal D, Steinbok P, Cocharane D. Pseudoclosure of anterior fontanele by Wormian bone in isolated sagittal craneosynostosis. Pedtr Neurosurg 2006;42:135-7.

33. Nallathamby R, Soman MA. Ossa wormiana - a morphological study. International Journal of Bioassays 2018;7:5668-73.

34. Natsis K, Piagkou M, Lazaridis N, Anastasopoulos N, Nousios G, Piagkos G, Loukas M. Incidence, number and topography of Wormian bones in Greek adult dry skulls. Folia Morphol (Warsz) 2019;78: 359-70.

35. Reddy U, Reddy V. Study of Wormian bones in adult dry skulls of human cadaver. Int J Anat Res 2018;6:5632-6.

36. de Heus G. The prevalence of accessory sutures and wormian bones in a contemporary cohort of Dutch children. [Internet] [Cited Oct 10, 2018]. Available from: http://scriptiesonline.uba.uva.nl/document/667178

Correspondence to: Rafael Romero-Reverón, MD Human Anatomy Department, J.M. Vargas School of Medicine, Universidad Central de Venezuela, Caracas, Venezuela Phone: +58416 6389552 e-mail: rafa1636@yahoo.es; RafaelRomeroReveron@yahoo.com.ve Conflict of interest statement: No conflicts declared.

This is an open access article distributed under the terms of the Creative Commons Attribution-NonCommercial-NoDerivs 3.0 Unported (CC BY-NCND3.0) Licence (http://creativecommons.org/licenses/by-nc-nd/3.0/) which permits unrestricted noncommercial use, distribution, and reproduction in any medium, provided the original work is properly cited. Please cite this article as: Romero-Reverón R, Arráez-Aybar LA. Sutural bones: a literature review. Anatomy 2019;13(1):61-65. 